\title{
Modulation of human B lymphocyte differentiation by therapeutic immunoglobulins: from protein to mRNA levels
}

\author{
Nathalie Dussault ${ }^{1}$, Nellie Dumont ${ }^{1}$, Sonia Néron ${ }^{1,2^{*}}$ \\ ${ }^{1}$ Recherche et Développement, Héma-Québec, Québec, Canada; ${ }^{*}$ Corresponding Author: sonia.neron@hema-quebec.qc.ca \\ ${ }^{2}$ Département de Biochimie et de Microbiologie, Université Laval, Québec, Qc, Canada.
}

Received 17 August 2011; revised 18 October 2011; accepted 11 November 2011.

\begin{abstract}
Several groups are investigating the mechanisms of action of therapeutic immunoglobulins (IVIg) in order to improve their use. In vitro models such as CD40-CD154 interaction are necessary to study the physiological response of human B lymphocytes to IVIg. Human B lymphocytes treated with IVIg triggers a rapid phosphorylation $(<1 \mathrm{~h})$ of extracellular-regulatedkinases 1 and 2 (ERK1/2), which subsequently results in increased differentiation and decreased proliferation. However, the modulation of human lymphocyte physiology by IVIg is a gradual and cumulative process and requires long-term experimentation. Differentiation of human B lymphocytes into Ig-secreting cells can be evaluated both at the transcription and translation levels. The secretion of immunoglobulins can be assessed using ELISA or ELISPOTS whereas expression of immunoglobulin genes can be measured using semi-quantitative or quantitative PCR methods. We hereby report a comparison of these methods to explain how contradictory observations towards IVIg effects could result from their use. Our results indicate that ELISA and ELISPOTS will provide consistent observations by opposition to real-time PCR quantification. Besides, the reliability of each of these methods remained dependent on the stimulation period as well as the preparation of cellular extracts or cell samples following IVIg-treatment.
\end{abstract}

Keywords: Human B Lymphocytes; CD40-CD154; IVIg; Differentiation; Immunomodulation

\section{INTRODUCTION}

Therapeutic immunoglobulins are constituted of $\operatorname{IgG}$ $(\geq 98 \%)$ and are used in the treatment of several inflammatory and autoimmune disorders in which IVIg have been shown to reestablish homeostasis [1]. Following IVIg injection, the concentration of IgG in the patient's serum increases by 5 to $10 \mathrm{mg} / \mathrm{mL}$ [2-4]. In many cases, treatment with IVIg results in the reduction or disappearance of pathologic autoimmune antibodies in the patient's serum for prolonged periods of time. Several studies have proposed that anti-idiotypic antibodies, present in IVIg, could interact with the B-cell receptor (BCR). By doing so, IVIg modulate autoreactive B lymphocytes [1]. According to this hypothesis, we showed that IVIg interaction with B lymphocytes results in phosphorylation of ERK1/2, which is downstream to BCR cross-linking [5]. We also showed that IVIg can directly modulate $\mathrm{B}$ lymphocytes by inducing secretion of IgG reacting with self- and non-self antigens in cells obtained from healthy individuals [6] as well as from patient with systemic lupus erythematosus [7]. In vitro models are important to study the mechanisms of action of IVIg and several groups are using the CD40-CD154 interaction to delineate their effects on human B lymphocytes. However, all in vitro models using this interaction are not equal [8]. Variations in the level of CD40CD154 interactions can result in phenotypic and functional differences in human B lymphocyte responses $[9,10]$ as well as in dendritic cells [11] and macrophages [12]. Cell fate determination toward proliferation or differentiation is directly proportional to the average number of CD154 molecules per B lymphocyte $[9,13]$. Essentially, low levels of CD40 occupancy (500 to 1000 CD154 molecules per B cell) result in high Ig secretion and low proliferation. Conversely, low Ig secretion and high proliferation is observed when using a high level of interaction (5000 to $10,000 \mathrm{CD} 154$ molecules per B cell) $[9,13]$. Moreover, sub-populations of human B lymphocytes will respond distinctively to variable intensity of CD40 stimulation [9,13-15]. Therefore, models based on in vitro $\mathrm{CD} 40$-activation of human $\mathrm{B}$ lymphocytes may 
lead to very contrasting physiological effects, which are as diverse as the nature of the ligands used to bind CD40 (reviewed in [8]). As a result and on the basis of our previous studies, the strength of IVIg modulation on B lymphocytes will depend on the level of CD40-CD154 interaction [7].

For the present work, we have used low and high levels of CD40-CD154 interaction and compared methods to assess the direct effect of IVIg on those B lymphocytes. We specifically targeted the differentiation status by using ELISA and ELISPOT methods to determine the secretion rates and the frequency of secreting cells and we used polymerase chain reaction (PCR), semi-quantitative PCR and real-time PCR (Q-PCR) to evaluate immunoglobulins' expression levels.

\section{MATERIALS AND METHODS}

\subsection{Intravenous Immunoglobulins}

Commercial preparation of GAMUNEX ${ }^{\circledR}$ IVIg containing $9 \%$ to $11 \%$ of protein and 160 to $240 \mathrm{mM}$ glycine, was obtained from Talecris (North Carolina, USA) and albumin from bovine serum (BSA, Cohn fraction V, Sigma-Aldrich Ltd, Oakville, ON, Canada) was prepared at $10 \%$ in $10 \mathrm{mM}$ phosphate buffered saline (PBS). IVIg and BSA preparations were dialysed against $10 \mathrm{mM}$ potassium/sodium phosphate containing $136 \mathrm{mM} \mathrm{NaCl}$ (PBS) (Gibco, Grand Island, NY, USA) and $40 \mathrm{mM}$ gly cine, pH4.5 (Sigma-Aldrich). After dialyse, IgG content in IVIg was mainly monomeric $(96 \%-98 \%)$ and the final concentration was $100 \mathrm{mg} / \mathrm{ml}$ [5]. BSA, which does not interfere with B-cell proliferation and $\operatorname{IgG}$ secretion [6], was used as a control for protein content.

\subsection{Human Peripheral B Lymphocytes}

This study has been reviewed and approved by HémaQuébec's Research Ethics Committee. Samples were obtained from healthy individuals after informed consent. Peripheral blood mononuclear cells (PBMNCs) were prepared from leucocytes recovered from leucoreduction system by density centrifugation over Ficoll-Paque (GE Healthcare Bio-Sciences Inc., Baie d'Urfé, QC, Canada) and stored frozen until B-cell purification as described previously [16]. B lymphocytes were purified by negative selection using the Easy Sep CD19 cocktail, according to the manufacturer's instructions (Stem Cell Technologies, Vancouver, BC, Canada) and were pure at $90 \%$ to $95 \%$ CD $19^{+}$cells, as determined by flow cytometry.

\subsection{CD40 Stimulation of B Lymphocytes}

L4.5 cell line is a genetically modified L929 cell line
(CCL-1, American Type Culture Collection, Manassas, VA) [17] expressing 21,000 \pm 4000 CD154 molecules per cell [9]. Purified B lymphocytes were seeded in Primaria plates (BD Labware) at $\sim 3.75 \times 10^{5}$ cells $/ \mathrm{mL}$ in the presence of $\gamma$-irradiated L4.5 cells expressing CD 154 [18]. L4.5 cells were seeded as to obtain ratios corresponding to high and low levels of CD40-stimulation, 3 - 5 or 20 - 25 B lymphocytes per L4.5 cell, respectively. B lymphocytes were cultured in a medium based on IMDM supplemented with $10 \%$ ultra low IgG FBS containing $10 \mathrm{~g} / \mathrm{mL}$ insulin, $5.5 \mathrm{~g} / \mathrm{mL}$ transferrin, $6.7 \mathrm{ng} / \mathrm{mL}$ sodium selenite, $100 \mu \mathrm{g} / \mathrm{ml}$ streptomycin and $100 \mathrm{U} / \mathrm{ml}$ penicillin $\mathrm{G}$ (all from Invitrogen, Burlington, ON, Canada), 50 U/mL IL-2, 25 U/mL IL-10 (PeproTech, Rocky Hill, NJ, USA) and $100 \mathrm{U} / \mathrm{mL}$ IL-4 (R\&D Systems, Minneapolis, MN, USA). This complete IMDM medium was used in all assays. B lymphocytes were stimulated with high or low level of CD40-CD154 interaction for 9 days in the presence or absence of $10 \mathrm{mg} / \mathrm{ml}$ of IVIg. When indicated, cells were cultured in the presence of $10 \mathrm{mg} / \mathrm{mL}$ of BSA or $4 \mathrm{mM}$ glycine $\mathrm{pH} 4.5$ as controls for IVIg-addition. Cultures were fed by replacing half of the culture medium every 2 - 3 days, while L4.5 cells were renewed every 4 - 5 days. Cell counts and viability were evaluated in triplicates by trypan blue dye exclusion using a hemacytometer. Cultured B lymphocytes were always $>96 \%$ CD $19^{+}$cells. Generation time $\left(\mathrm{T}_{\text {gen }}\right)$ was calculated according to the formula: $\kappa=1 / \ln 2$ $\ln 2\left[\mathrm{~N}_{\mathrm{t} 2}\right]-\ln \left[\mathrm{N}_{\mathrm{t} 1}\right] / \mathrm{t}_{2}-\mathrm{t}_{1}$ and $\mathrm{T}_{\text {gen }}=1 / \kappa$.

\subsection{ELISA}

For the determination of $\mathrm{IgG}$ and $\mathrm{IgM}$ secretion rate, cells were harvested and washed 5 times to remove residual IVIg with PBS containing $2 \mathrm{~g} / \mathrm{L}$ of glucose (PBSsglc). To validate that the secretion by the treated cells was de novo protein synthesis, the washed cells were incubated in complete IMDM medium for three hours in the presence or absence of $15 \mu \mathrm{g} / \mathrm{ml}$ cycloheximide (CHX). At this step these $3 \mathrm{~h}$-supernatants were kept and the cells were washed in PBS-glc and seeded at 1 $2 \times 10^{6}$ cells $/ \mathrm{mL}$ in IMDM medium alone for 18 to 22 hours. IgG and IgM concentrations were determined in a standard ELISA using plastic-adsorbed goat antibodies specific to human $\gamma$ - and $\mu$-chains and the bound IgG or IgM were both revealed with peroxidase conjugated goat polyvalent anti-human Ig antibodies. All antibodies were obtained from Jackson Laboratories (Mississauga, Canada).

\subsection{ELISPOTS}

B lymphocytes, untreated or treated with IVIg, were washed 5 times in PBS-glc, transferred in IMDM containing $10 \%$ FBS and incubated for 3 hours with or 
without $15 \mu \mathrm{g} / \mathrm{mL}$ CHX. B lymphocytes were washed and plated in 96-well Multiscreen IP sterile plate (Milli-pore, Billerica, MA, USA) adsorbed with goat anti-bodyies specific to human $\gamma$-chain following manufacturer's instructions. B lymphocytes were added in triplicates using serial dilutions varying from 20,000 to 156 cells/well, and incubated overnight at $37^{\circ} \mathrm{C}$ in a $\mathrm{CO}_{2}$-incubator. Plates were washed with $0.85 \% \mathrm{NaCl}$ and incubated with peroxidase-conjugated goat polyvalent anti-human $\mathrm{Ig}$ antibodies for $2 \mathrm{~h}$ at $37^{\circ} \mathrm{C}$ in $10 \% \mathrm{CO}_{2}$. All antibodies were obtained from Jackson Laboratories. Spots were revealed by incubation with TrueBlue TMB Peroxidase Substrate (Mandel Scientific Cie Inc., Guelph, Canada) for 30 minutes at room temperature. Membranes were washed and dried overnight in the dark and their numbers were determined using a microscope. The frequency of secreting cells was determined by dividing the number of spot units by the amount of seeded cells for at least two successive dilutions.

\subsection{Reverse Transcriptase-PCR and Semi-Quantitative PCR}

Purified B lymphocytes stimulated as described above, in absence (CTL) or presence of $10 \mathrm{mg} / \mathrm{ml} \mathrm{BSA}$ or 10 $\mathrm{mg} / \mathrm{ml}$ IVIg, were washed 5 times to remove IVIg. RNA extraction was performed using High Pure RNA isolation kit (Roche diagnostics, Indianapolis, IN, USA) according to the manufacturer's instructions. RNA was treated with DNAse Amp grade (Invitrogen) and firststrand cDNA was synthesized using M-MLV RT (Invitrogen). PCR was performed on PCRExpress (ThermoHybaid, Ashford, UK) using AmpliTaq Gold (Applied Biosystems, Foster City, CA, USA) following manufacturer's instructions. Amplification of gamma regions of $\mathrm{IgG}_{1}, \mathrm{IgG}_{2}, \mathrm{IgG}_{3}, \operatorname{IgG}_{4}[19]$ and $\operatorname{IgG}_{1}-\mathrm{S}, \operatorname{IgG}_{2-4}$ [20], was done using the primer combinations listed in Table $\mathbf{1}$, at $95^{\circ} \mathrm{C}$ for 5 minutes followed by 35 -cycles at $95^{\circ} \mathrm{C}$ for 15 seconds and $60^{\circ} \mathrm{C}$ for 30 seconds, with a final elongation step at $72^{\circ} \mathrm{C}$ for 6 minutes. Semi-quantitative PCR was performed using the same method, but using an initial denaturation at $95^{\circ} \mathrm{C}$ for 5 minutes, followed by $15,20,25$, 30 and 35 PCR cycles. All PCR products were separated by electrophoresis on a $2 \%$ agarose gel (Invitrogen).

\subsection{Quantitative Real-Time-PCR}

Q-PCR was performed on Stratagene Mx3005P QPCR system using PerfeCta SYBR ${ }^{\circledR}$ Green FastMix ${ }^{\text {TM }}$ (Quanta Bioscience Gaithersburg, MD, USA) and master Mix 1 following manufacturer's instructions. Amplification of gamma region of $\mathrm{IgG}, \mathrm{IgG}_{1}, \mathrm{IgG}_{2}, \mathrm{IgG}_{3}$ and $\mathrm{IgG}_{4}$, as well as glyceraldehyde-3-phosphate dehydrogenase (GAPDH) [21,22] or 18S ribosomal RNA [20] as en-
Table 1. Primers for PCR and Q-PCR.

\begin{tabular}{|c|c|c|c|}
\hline \multirow{2}{*}{$\operatorname{IgG}$} & $\mathrm{F}^{1}$ & CAAGGACTACTTCCCCGAAC & \multirow{2}{*}{$200^{2}$} \\
\hline & $\mathrm{R}$ & TCTTGTCCACCTTGGTGTTTG & \\
\hline \multirow{2}{*}{$\mathrm{IgG}_{1}$} & $\mathrm{~F}$ & GCATGTACTAGTTTTGTCACAAGATTTGGG & \multirow{2}{*}{300} \\
\hline & $\mathrm{R}$ & TCCACCAAGGGCCCATCG & \\
\hline \multirow{2}{*}{$\mathrm{IgG}_{2}$} & $\mathrm{~F}$ & CTCGACACTAGTTTTGCCGCTCAACTGTCTT & \multirow{2}{*}{300} \\
\hline & $\mathrm{R}$ & TCCACCAAGGGCCCATCG & \\
\hline \multirow{2}{*}{$\operatorname{IgG}_{3}$} & $\mathrm{~F}$ & TGTGTGACTAGTGTCACCAAGTGGGGTTTT & \multirow{2}{*}{300} \\
\hline & $\mathrm{R}$ & TCCACCAAGGGCCCATCG & \\
\hline \multirow{2}{*}{$\mathrm{IgG}_{4}$} & $\mathrm{~F}$ & GCATGAACTAGTTGGGGGACCATATTTGGA & \multirow{2}{*}{300} \\
\hline & $\mathrm{R}$ & GCTTCCACCAAGGGCCCATC & \\
\hline \multirow{2}{*}{$\mathrm{IgG}_{1}-\mathrm{S}$} & $\mathrm{F}$ & CATCTCCAAAGCCAAAGG & \multirow{2}{*}{150} \\
\hline & $\mathrm{R}$ & ATGTCGCTGGGATAGAAG & \\
\hline \multirow{2}{*}{$\operatorname{IgG}_{2-4}$} & $\mathrm{~F}$ & CATCTCCAAAGCCAAAGG & \multirow{2}{*}{150} \\
\hline & $\mathrm{R}$ & ATGTCGCTGGGGTAGAAG & \\
\hline \multirow{2}{*}{$\begin{array}{c}\text { GAPD } \\
\mathrm{H}\end{array}$} & $\mathrm{F}$ & CGAGATCCCTCCAAAATCAA & \multirow{2}{*}{300} \\
\hline & $\mathrm{R}$ & GTCTTCTGGGTGGCAGTGAT & \\
\hline \multirow{2}{*}{$\begin{array}{c}18 \mathrm{~S} \\
\text { rRNA }\end{array}$} & $\mathrm{F}$ & AGTCCCTGCCCTTTGTACACA & \multirow{2}{*}{68} \\
\hline & $\mathrm{R}$ & GATCCGAGGGCCTCACTAAAC & \\
\hline
\end{tabular}

${ }^{1}$ Forward (F); Reverse (R) ${ }^{2}$ Amplicon (nts).

dogenous control genes, was done using the primers listed in Table 1. Amplification of gamma region of $\mathrm{IgG}$ and GAPDH yielded amplicons of $\sim 300 \mathrm{nt}$. When indicated quantification of GAPDH or $18 \mathrm{~S}$ rRNA was performed for each sample; allowing normalization of samples as previously described [23]. Dissociation curve analysis was performed to obtain the amplification of a single PCR product. Quantification of the transcripts was carried out with the software Mx3005P version 2.02 (Invitrogen) using the comparative threshold cycle $2^{-\Delta \Delta C t}$ method.

\subsection{Statistical Analysis}

When indicated, the mean values \pm standard deviations or standard error of the mean (SEM) were calculated, data distribution was evaluated using the ShapiroWilk test and analysis of variance was done using the F-test. Thereafter, statistical significance between tests and controls was determined using Mann-Whitney Utest or two-sided Student's paired t-test.

\section{RESULTS}

\subsection{IVIg and B Lymphocyte Proliferation}

Human B lymphocytes, isolated from 6 independent samples were stimulated with high or low level of CD154 and cultured for 9 days, in the presence or absence of $10 \mathrm{mg} / \mathrm{ml} \mathrm{IVIg.} \mathrm{IVIg} \mathrm{were} \mathrm{added} \mathrm{from} \mathrm{the} \mathrm{start} \mathrm{and}$ 
maintained in medium renewal for the duration of the culture (Figure 1). Total expansion was determined over the 9-day culture period (Figure 1(a)) and $\mathrm{T}_{\text {gen }}$ was determined for cells receiving high (Figure 1(b)) and low (Figure 1(c)) CD40-CD154 interaction within the exponential growth phase, namely between days 4 and 9 . As previously reported $[9,13], \mathrm{T}_{\text {gen }}$ mean value appeared higher for cells submitted to low ( $54 \pm 16$ hours) than for those submitted to high ( $43 \pm 15$ hours) CD154 interaction. However, this tendency was not statistically different $(p=0.267)$. In both cases, addition of IVIg signifycantly increased the $\mathrm{T}_{\text {gen }}$ by about $20 \%$ when compared to untreated cells: $52 \pm 17$ hours and $63 \pm 23$ hours for cells submitted to high and low level of CD154 interaction, respectively. Worthy of note, there was no difference in growth rate during the initiation phase, from day 0 to 4 , whether the cells were submitted to high or low CD40-stimulation and in presence or absence of IVIg. Essentially, these 6 independent experiments showed that significant IVIg reduction of B lymphocyte proliferation was observed only after a 9-day IVIg treatment in cells maintained in exponential growth.

\subsection{Residual IgG in B Lymphocyte Sample Following IVIg Treatment}

In vitro IVIg treatment of B lymphocytes using 10 $\mathrm{mg} / \mathrm{ml}$ or higher concentrations is highly problematic for the determination of IVIg effects on IgG secretion. However, we previously reported [6] that such measurements can be done when using cells that have been washed extensively and seeded back to secrete in absence of IVIg for a short period $(<24 \mathrm{~h})$. To illustrate how important and efficient was the repeated washings of $\mathrm{B}$ lymphocytes, we have measured the residual $\mathrm{IgG}$ content in washing supernatants of IVIg treated-cells (Figure 2). A minimum of 5 washing steps were needed to decrease the concentration of IgG (IVIg) from $10 \mathrm{mg} / \mathrm{ml}$ to less than $500 \mathrm{ng} / \mathrm{mL}$ of IgG. These successive washes also resulted in the recovery of a final amount of $2-4 \times 10^{6}$ cells, representing less than $30 \%$ of the cells collected at the end of the culture period. Therefore, when 18 to 21 hours-secretion periods were evaluated, the IgG content coming from IVIg could correspond to a residual concentration of 125 to $250 \mathrm{ng}$ per $10^{6}$ cells.

\subsection{IVIg Increase Differentiation into IgG-Secreting Cells}

As described in Figure 1, cultured B lymphocytes were washed and treated for 3 hours in the presence or absence of CHX. Then, these 3 h-treated B lymphocytes were washed once more and seeded back in culturemedium for 18 hours to 21 hours. This two-step incubation enables us to discriminate between de novo synthesis

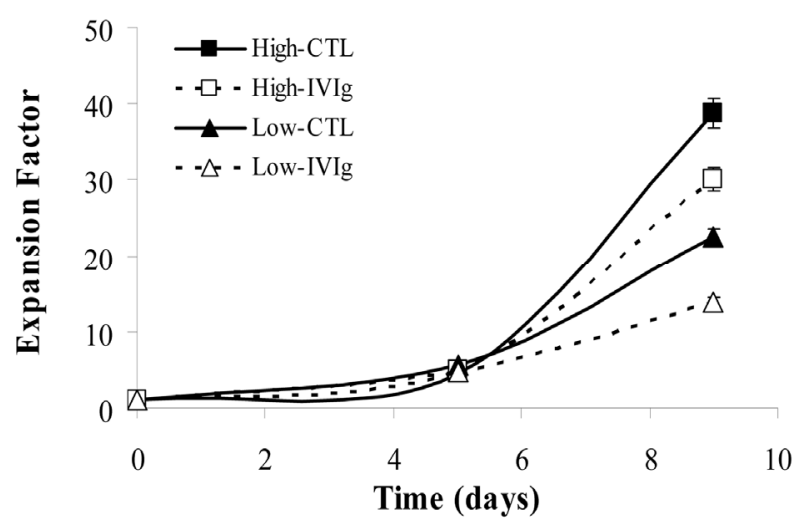

(a)

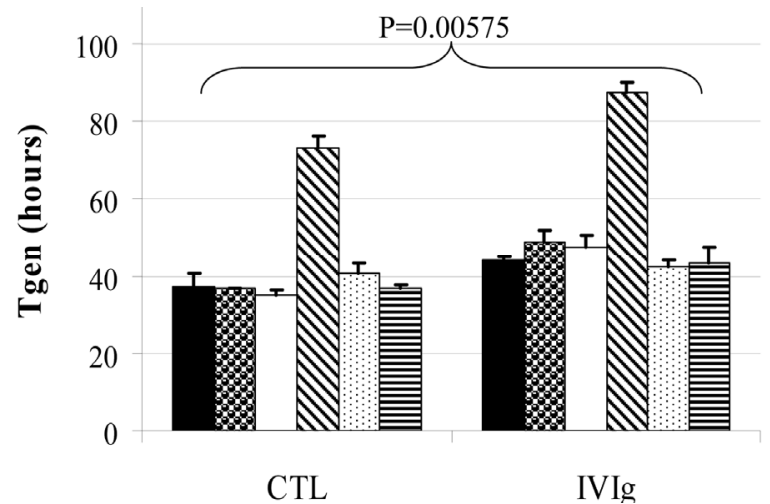

(b)

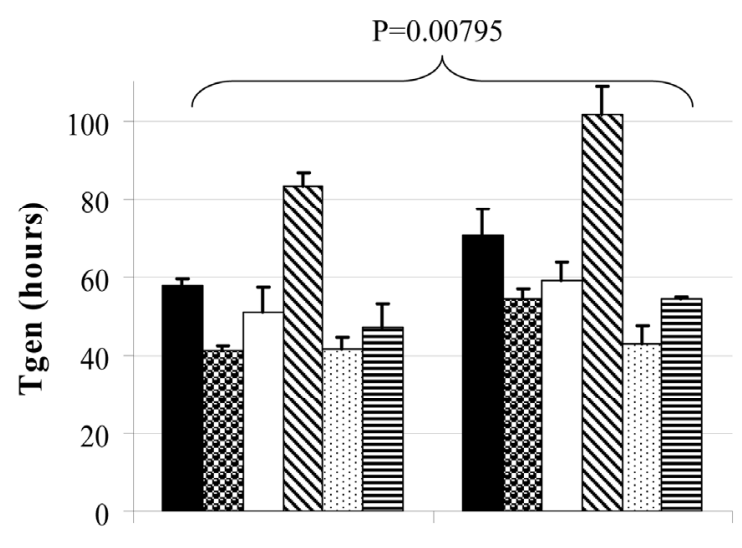

CTL

IVIg

(c)

Human B lymphocytes ( $>95 \%$ CD $19^{+}$cells) stimulated for 9 days with high (square symbols) and low levels (triangle symbols) of CD154 interaction in presence (IVIg; empty symbols) of $10 \mathrm{mg} / \mathrm{ml} \mathrm{IVIg}$ or with an identical volume of 40mM glycine buffer (CTL; filled symbols). Error bars for triplicates, can be smaller than symbols. These results are representative of 6 independent experiments. Generation time values $\left(\mathrm{T}_{\text {gen }}\right)$ for B lymphocytes exposed to high (b) and low (c) level of CD154 are showed for 6 independent samples. P values for $\mathrm{T}_{\text {gen }}$ comparing IVIg-treated and untreated cells were determined using two-sided Student's paired t-test and correlation coefficient were $\mathrm{r}=$ 0.968 (B) and $r=0.982$ (c). In B and C, each histogram pattern stands for one sample. For example filled histograms in B and C are the same sample \pm IVIg in both conditions.

Figure 1. IVIg inhibit B lymphocyte proliferation. 


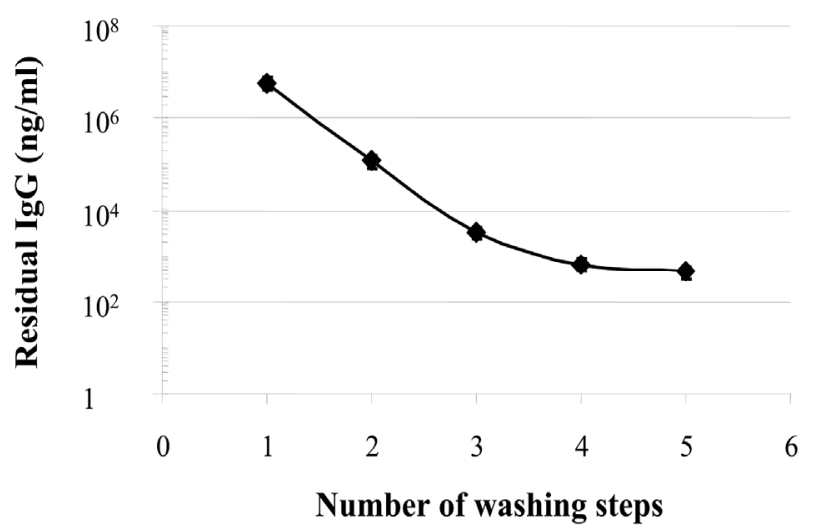

Figure 2. Removal of $99 \%$ of residual IgG in IVIg treated cells. B lymphocytes have been stimulated with high or low CD154 interaction, as described in Figure 1, in the presence of 10 $\mathrm{mg} / \mathrm{mL}$ IVIg for 9 days. A total number of $16-20 \times 10^{6}$ cells were washed with PBS-glc 5 times. IgG content was measured in each washing supernatants by ELISA. Data are presented as the mean $\pm \mathrm{SD}$ of 3 independent experiments.

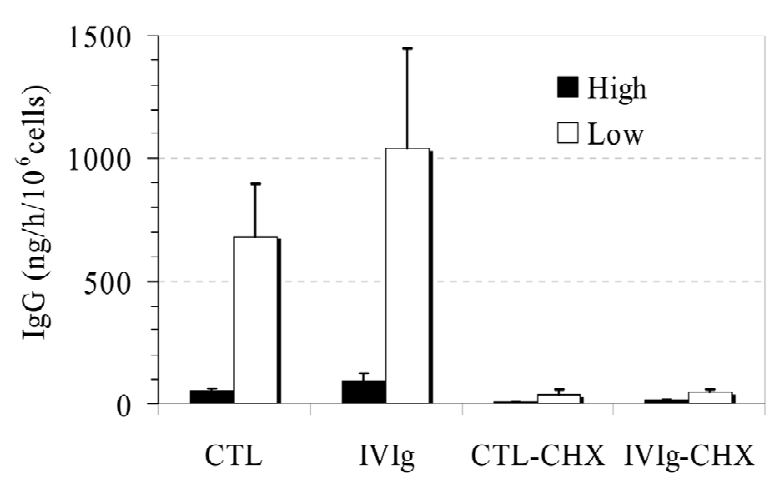

(a)

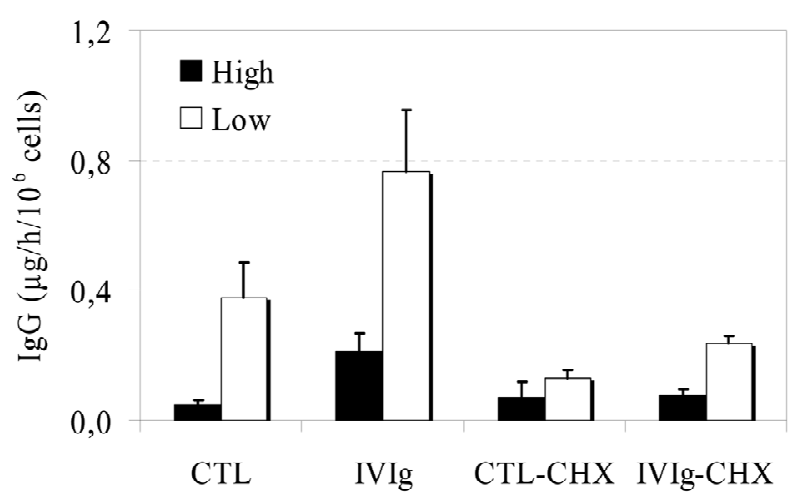

(c) of IgG following IVIg treatment and releasing of IVIg, which could occur following spontaneous internalization [24]. IgG and IgM secretion rates were established for 6 independent samples following incubation in the presence or absence of IVIg and compared to CHX-treated cells (Figures 3(a)-(b)). This CHX-treatment inhibited IgG and IgM secretion by more than $80 \%$ for at least 18 to 21 hours (Figures 3(a)-(b)) and inhibition of protein synthesis was already noticeable after 3 hours (Figure 3(c)). As suggested by the large SEM (Figure 3), such in vitro CD40-activation is characterized by inter-individual variability in the human B lymphocytes response $[7,9,15,25]$. Still, the comparison of 6 experiments using two-sided Student's paired t-test allowed us to highlight significant differences.

Human B lymphocytes submitted to high levels of CD40-CD154 interaction and treated with IVIg were secreting 18 to $208 \mathrm{ng}$ of $\mathrm{IgG} / \mathrm{h} / 10^{6}$ cells (mean $\pm \mathrm{SD} ; 97$ \pm 70 ) while control cells were secreting 6 to $89 \mathrm{ng}$ of

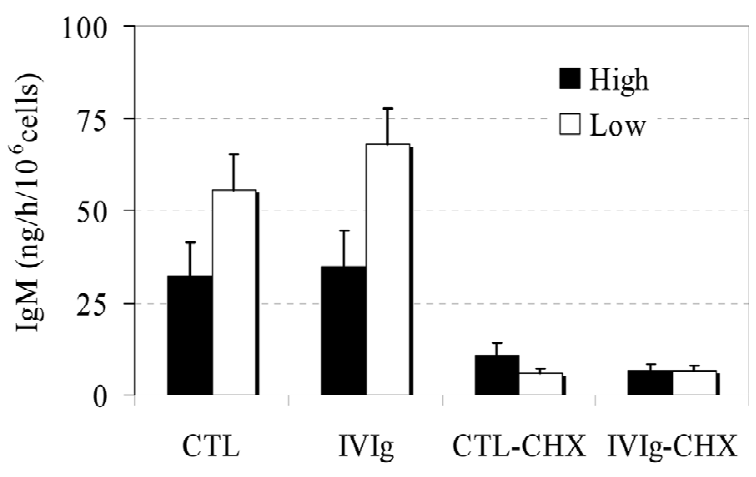

(b)

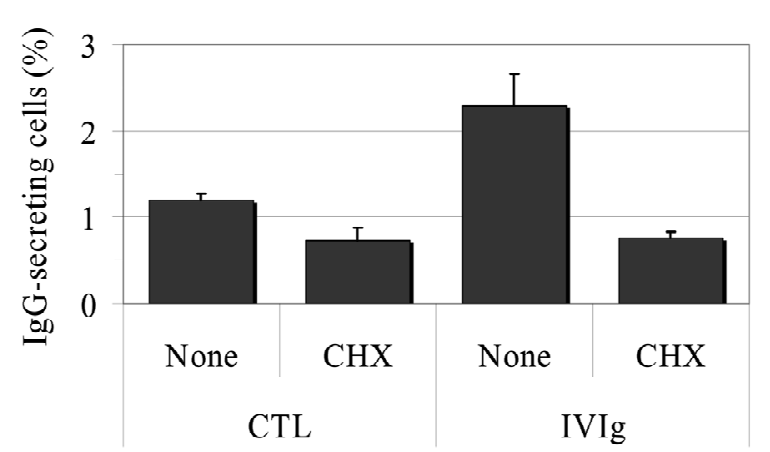

(d)

Figure 3. IVIg-increased de novo IgG secretion. B lymphocytes were stimulated as described in Figure 1. On day 9, cells were washed 5 times and incubated 3 hours in the absence or presence of $15 \mu \mathrm{g} / \mathrm{mL}$ cycloheximide (CHX). Cells were washed and then seeded back in IMDM alone for a supplemental 18 to $20 \mathrm{~h}$. IgG and IgM contents were determined in these supernatants ((a) and (b)) and in the 3 h-supernatant (c). The frequency of IgG-secreting cells was determined by a standard ELISPOT (d). Data presented in A and $B$ are the mean \pm SEM of six independent experiments while results presented in (c) are the mean \pm SEM of four independent experiments. The IVIg increase of IgG secretion in B lymphocytes submitted to high $(p=0.030)$ and low $(p=0.09)$ levels of CD40-CD154 interaction is significant according to paired t-test while no significant difference was observed for IgM secretion ((a) and (b)). The IVIg induced IgG secretion during CHX-treatment is significant for cells submitted to high level of CD40-CD154 interaction $(\mathrm{U}=2,309 ; \mathrm{p}=0.0209)$. 
$\mathrm{IgG} / \mathrm{h} / 10^{6}$ cells (mean $\pm \mathrm{SD} ; 50 \pm 35$ ). Thus, high levels of CD40-CD154 interaction clearly led to a statistically significant IVIg-increase of IgG secretion $(p=0.0300)$. On the other hand, human B lymphocytes submitted to low stimulation in the presence of IVIg were secreting 111 to $2951 \mathrm{ng}$ of $\mathrm{IgG} / \mathrm{h} / 10^{6}$ cells (mean $\pm \mathrm{SD} ; 1042 \pm$ 1014) while untreated cells were secreting 65 to $1550 \mathrm{ng}$ of $\mathrm{IgG} / \mathrm{h} / 10^{6}$ cells (mean $\pm \mathrm{SD} ; 681 \pm 544$ ). Such an increase of IgG secretion $(p=0.09)$, namely about 1.5 -fold, corresponds to a supplemental secretion of $362 \pm 513 \mathrm{ng}$ of IgG/h/ $/ 10^{6}$ cells. In contrast, IVIg did not modulate de novo IgM secretion by B lymphocytes submitted to low and high level of CD40-CD154 interaction (Figure 3(b)).

$\mathrm{IgG}$ content in the supernatant from CHX-treated cells in 4 independent experiments was also assessed (Figure 3(c)). IVIg increased IgG secretion by 1.8 -fold and 4.6fold for cells submitted to low and high level of CD40CD154 interaction, respectively. We have also measured $\mathrm{IgG}$ de novo synthesis by ELISPOT using CHX treatedcells (Figure 3(d)). On day 9, the frequency of IgG secreting cells detected by ELISPOT assay was very low $(<3 \%)$, nonetheless IVIg still appeared to slightly increase the frequency of IgG-secreting cells.

We have previously shown that IVIg-treatment of human B lymphocytes increases IgG secretion in longterm culture, namely 14 days [5-7]. These results further substantiate that IVIg can increase the de novo IgG secretion in CD40-activated B lymphocytes after a 9-day treatment (Figure 1).

\subsection{IVIg Modulation and mRNA Synthesis}

B lymphocytes were cultured for 9 days, as above (Figure 1), in the presence or absence of IVIg. In this case, controls were treated with PBS- $40 \mathrm{mM}$ glycine $\mathrm{pH}$ 4.5 (CTL) and BSA as indicated methods. RT-PCR was used to verify whether all 5 sets of primers used efficiently detected gamma chains as well as subclasses such as $\mathrm{IgG}_{1}, \mathrm{IgG}_{2}$ and $\mathrm{IgG}_{3}$ and $\operatorname{IgG}_{4}$ (Figures 4(a) and (b)). Except for the primers used to detect $\operatorname{IgG}_{3}$, all sets of primers used were reliable to detect the various IgG mRNA from controls cells as well as cells treated with
BSA or IVIg. $\operatorname{IgG}_{3}$ mRNA was however detected in some samples but showed no increase in IVIg-treated cells (data not shown). For the set of primers used in to detect $\operatorname{IgG}_{1}$ and $\operatorname{IgG}_{2}$ (Figure 4 (b)), these analyses, which have been done up to 4 times on 3 independent samples, showed an increase in IgG mRNA content following IVIg treatment. However, these observations were not consistent with the other sets of primers used targeting the same mRNA.

Using semi-quantitative PCR, we evaluated whether IVIg modulation of IgG transcription can be detected (Figure 4 (c)). In this case, the two sets of primers used in panel $\mathrm{A}$ target $\operatorname{IgG}_{1}\left(\mathrm{IgG}_{1-\mathrm{S}}\right)$ and $\mathrm{IgG}_{2}, \mathrm{IgG}_{3}$ and $\mathrm{IgG}_{4}$ $\left(\operatorname{IgG}_{2-4}\right)$ [20]. Although the quantitative aspect was improved when compared to the RT-PCR experiments, there was no increase in the IgG mRNA levels following IVIg treatment when compared to untreated cells. BSAtreated cells displayed lower expression levels of $\mathrm{IgG}_{1}$ mRNA than untreated cells or IVIg-treated cells. These results did not reveal any significant effect of IVIg and were contradictory with the observed increased of IgG protein, as determined by ELISA, for the same experiment and samples. For example, panel A and B correspond to a culture where $\mathrm{IgG}$ secretion was increased by 2-fold in IVIg treated cells when compared to BSAtreated cells and untreated cells, which were giving identical $\mathrm{IgG}$ secretion.

Q-PCR analyses were performed to compare the mRNA expression of untreated cells and BSA-treated cells to IVIg-treated cells (Figure 5). Relative IgG mRNA content varied depending on the housekeeping gene used and depending on whether IVIg-cells were compared to untreated or BSA-treated cells. The twofold increase, which is usually considered as a significant difference in Q-PCR analysis, was not observed when IVIg conditions were compared to untreated cells. Once again, IVIg appeared to significantly increase $\operatorname{IgG}_{1}$ and $\mathrm{IgG}_{2}$ expression when compared to the BSA condition.

Overall, neither semi-quantitative PCR nor Q-PCR detected an increased IgG secretion in human B lymphocytes with IVIg. Furthermore, these experiments carried out using 3 independent samples were fluctuating depending on the samples used.

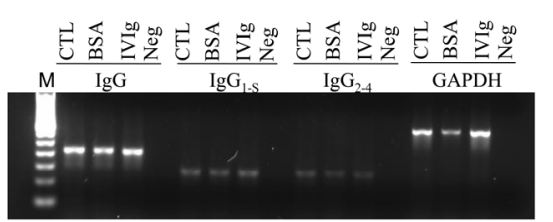

(a)

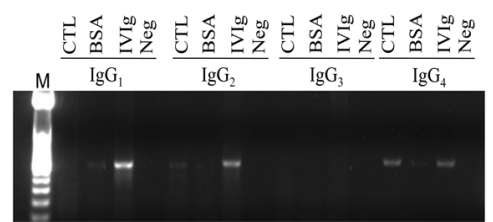

(b)

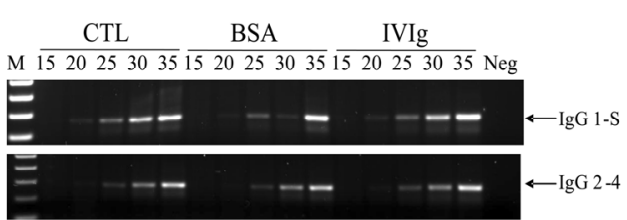

(c)

Figure 4. IgG mRNA is not influenced by IVIg. B lymphocytes were stimulated for 9 days with low levels of CD40-CD154 interaction in the presence or absence of $10 \mathrm{mg} / \mathrm{mL}$ bovine serum albumin (BSA) or $10 \mathrm{mg} / \mathrm{mL}$ IVIg (IVIg) both dialyzed in $40 \mathrm{mM}$ glycine $\mathrm{pH} 4.5$. For controls, $10 \%(\mathrm{v} / \mathrm{v}) 40 \mathrm{mM}$ glycine $\mathrm{pH} 4.5$ was added in the culture medium (CTL). IgG mRNA levels were evaluated using PCR method ((a) and (b)) and semi-quantitative PCR (c) with primers (Table 1) specifically targeting $\operatorname{IgG}_{1} \operatorname{IgG}_{1-\mathrm{s}}, \operatorname{IgG}_{2-4}, \operatorname{IgG}_{1}$, $\mathrm{IgG}_{2} \mathrm{IgG}_{3}$ and $\mathrm{IgG}_{4}$ gamma chains, and $\mathrm{GAPDH}$, as indicated at the top of the panels. 


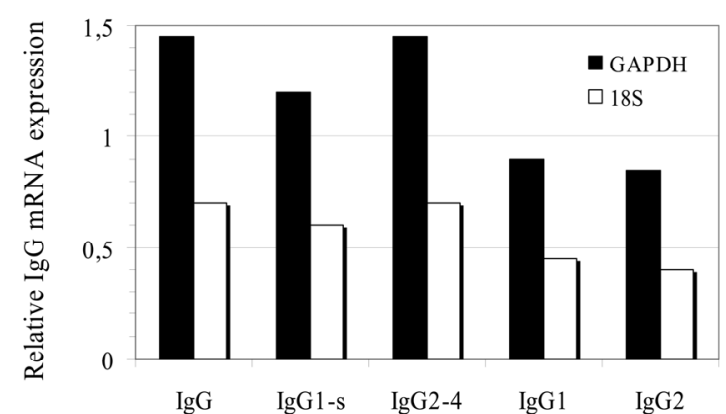

(a)

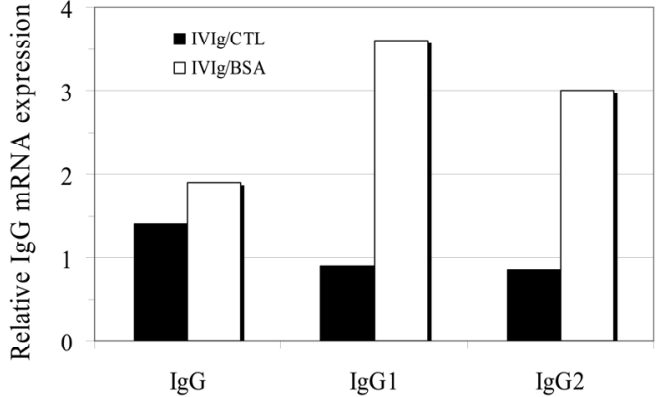

(b)

Figure 5. Q-PCR does not correlate with IVIg modulation of IgG. B lymphocytes were stimulated as above (Figure 4). In (a), two housekeeping genes, GAPDH (filled histograms) and 18S rRNA (Shaded histograms), relative expression values are obtained by comparing IVIg-treated cells to controls cells. In (b), relative values are for IVIg-treated cells compared to control (CTL; filled histograms) or BSA-treated cells (BSA; hatched histograms) using GAPDH as a reference gene.

\section{Discussion}

We have previously shown that IVIg can have direct effects on B lymphocytes [5-7]. Essentially, IVIg modulation of human B lymphocytes translates into a diminution of proliferation concomitant to an augmentation of Ig secretion. Such an increase in the secretion of human IgG is caused by de novo synthesis, which has been shown using metabolic labeling with ${ }^{35} \mathrm{~S}$-methionine [6]. On the other hand, we have also highlighted that variation in the intensity of CD40-CD154 interaction can strongly modulate the evolution of human blood B lymphocytes and alter the outcome of naïve and memory populations $[8,9,13]$ as well as their modulation by IVIg [7]. Therefore, interpretation of IVIg-modulation of human B lymphocytes, using such in vitro models, depends on the nature and strength of CD40 interaction and might be a source of discrepancy between studies.

In this study, we used high and low level of CD40stimulation in a cell-to-cell stimulus provided by $\mathrm{CD}$ $154^{+} \mathrm{L}$ cells [17] and human B lymphocytes treated with $10 \mathrm{mg} / \mathrm{mL}$ of IVIg as previously done [7]. As expected, proliferation was delayed in IVIg-treated cells and differentiation was down-regulated and these changes were also dependent on the level of CD40 stimulation.

The study of IVIg modulation of human B lymphocyte differentiation is limited by the in vitro treatment because IVIg interfere with the measurements of IgG secretion in the IVIg-treated cells [20,26]. To minimize the contribution of IVIg in IgG measurements, we constantly perform extensive washing of the treated cells [5-7]. We show that these procedures effectively remove $99.9 \%$ of residual $\mathrm{IgG}$, which is less than $500 \mathrm{ng} / \mathrm{mL}$. On the other hand, the extensive washings induce the loss of $60 \%-70 \%$ of the cells during centrifugation, which is a drawback when the amount of B lymphocytes is somewhat limited. Moreover, IVIg treatment not only precludes direct IgG measurements in culture supernatants, but may also have potential interferences caused by its high protein content, as recently reported for proliferation assays based on BrdU incorporation [27]. Therefore, extensive washings should be done even if the assays are not related to IgG measurements in order to avoid unwanted interferences.

To support the measurements of enhanced differentiation in IVIg-treated cells, we further emphasize on de novo synthesis by using protein synthesis inhibitor [28] in combination to ELISA or ELISPOT assays. The cycloheximide treatment confirmed that IVIg induction of IgG secretion and enhancement of IgG secreting cells are mainly caused by novel synthesis.

In this study, we also investigated the effect of IVIg on mRNA levels using PCR, semi-quantitative PCR and Q-PCR as previously done [20]. All analyses were done after 9 days of culture in the presence or absence of IVIg, in conditions where human B lymphocytes exhibit generation times $\left(\mathrm{T}_{\text {gen }}\right)$ ranging from 30 to 70 hours [15]. Although we have used several sets of primers amplifying any gamma chain as well as primers specific to each gamma 1 to gamma 4 subclasses, our results were inconclusive mostly because not reproducible from one samples to another. Worthy of note, such Q-PCR analysis is adequate to monitor the 10 -fold increase in $\operatorname{IgG}$ secretion in B lymphocytes stimulated with low compared to high CD40-CD154 interaction (data not shown).

The use of BSA as a control for IVIg addition is once more questionable [7]. Semi-quantitative analyses showed lower expression levels of $\mathrm{IgG}_{1}$ mRNA in BSA-treated cells compared to untreated cells. Similar results were obtained with Q-PCR analyses where BSA inhibits IgG mRNA expression when compared to untreated cells (data not shown). Besides, we observed a down regulation of GAPDH mRNA expression in the BSA-treated cells. GAPDH is considered as a protein content control by many investigators. Therefore, when comparing IVIgtreated cells to BSA-treated cells, increase mRNA expression could be incorrectly interpreted as a relative higher expression for IVIg-treated cells. Those results 
confirm previous studies showing that BSA have properties that make it unsuitable as a placebo [29].

On the other hand, the use of Q-PCR to monitor IVIg modulation of $\operatorname{IgG}$ secretion is questionable, particularly since a maximum of twofold increase secretion is often observed. Besides, these twofold changes are not valid in Q-PCR determination. In fact, the choice of reference "housekeeping" genes can greatly influence the normalization results and can vary from one type of cells to another. As example, the choice of $18 \mathrm{~S}$ rRNA to monitor IVIg treatment [20], which reliability may vary from one tissue to another $[21,22,30]$ and is particularly inconsistant in T lymphocytes [31]. Our Q-PCR analyses show a maximum increase of 1.6-fold in IgG mRNA expression following IVIg treatment, which is not considered significant for this method. In a certain point of view, these results are contradictory with the ELISA conclusion but are in agreement with those of Heidt and collaborators [20] stating that IVIg had no effect on IgG secretion according Q-PCR analysis of mRNA levels.

To avoid IVIg interferences, the quantification of IgM secretion have been previously used to monitor IVIg influence on the immunoglobulin production in common variable immunodeficiency, which was quite significant [26]. However, $\operatorname{IgM}$ secretion is restricted to naïve and memory subsets of B lymphocytes and is not representative of switched memory B lymphocytes. Moreover, our results indicated that IVIg effects on IgM secretion was less important and not significant compared to that on IgG synthesis. Therefore, the method described here represents an acceptable option to monitor the direct effect of IVIg on B lymphocytes differentiation. Furthermore, variations in the nature and intensity of CD40 binding during in vitro activation of human B lymphocytes will result in the emergence of distinct B-cell populations [9], which might in turn give rise to differential responses to IVIg [7].

In conclusion, by delimiting the strength and weakness in ELISA and PCR methods used to monitor IVIg effects on human B lymphocytes, this study intend to contribute to a better understanding of the mechanisms of action of IVIg from the protein to the mRNA level.

\section{ACKNOWLEDGEMENTS}

We thank all the volunteers who participated in this study and Claudine Côté Inf. for scheduling blood sample collection. We are grateful to Marc Cloutier Ph.D. for excellent critical review and manuscript editing.

\section{REFERENCES}

[1] Durandy, A., Kaveri, S. V., Kuijpers, T. W., Basta, M., Miescher, S., Ravetch, J. V. and Rieben, R. (2009) Intra- venous immunoglobulins - Understanding properties and mechanisms. Clinical \& Experimental Immunology, 158, 2-13. doi:10.1111/j.1365-2249.2009.04022.x

[2] Wasserman, R.L., Irani, A.M., Tracy, J., Tsoukas, C., Stark, D., Levy, R., Chen, J., Sorrells, S., Roberts, R. and Gupta, S. (2010) Pharmacokinetics and safety of subcutaneous immune globulin (human), 10\% caprylate/ chromatography purified in patients with primary immunodeficiency disease. Clinical \& Experimental Immunology, 161, 518-526. doi:10.1111/j.1365-2249.2010.04195.x

[3] Kreuz, W., Erdos, M., Rossi, P., Bernatowska, E., Espanol, T. and Marodi, L. (2010) A multi-centre study of efficacy and safety of Intratect((R)), a novel intravenous immunoglobulin preparation. Clinical \& Experimental Immunology, 101, 512-517. doi:10.1111/j.1365-2249.2010.04187.x

[4] Kuitwaard, K., de Gelder, J., Tio-Gillen, A. P., Hop, W.C., van Gelder, T., van Toorenenbergen, A.W., van Doorn, P.A. and Jacobs, B.C. (2009) Pharmacokinetics of intravenous immunoglobulin and outcome in Guillain-Barre syndrome. Annals of Neurology, 66, 597-603. doi:10.1002/ana.21737

[5] Dussault, N., Ducas, E., Racine, C., Jacques, A., Pare, I., Cote S. and Neron, S. (2008) Immunomodulation of human B cells following treatment with intravenous immunoglobulins involves increased phosphorylation of extracellular signal-regulated kinases 1 and 2. International Immunology, 20, 1369-1379. doi:10.1093/intimm/dxn090

[6] de Grandmont, M.J., Racine, C., Roy, A., Lemieux, R. and Néron, S. (2003) Intravenous immunoglobulins induce the in vitro differentiation of human B lymphocytes and the secretion of IgG. Blood, 101, 3065-3073.

doi:10.1182/blood-2002-06-1684

[7] Néron, S., Boire, G., Dussault, N., Racine, C., de BrumFernandes, A. J., Cote S. and Jacques, A. (2009) CD40activated B cells from patients with systemic lupus erythematosus can be modulated by therapeutic immunoglobulins in vitro. Archivum Immunologiae et Therapiae Experimentalis, 57, 447-458. doi:10.1007/s00005-009-0048-3

[8] Néron, S., Nadeau, P.J., Darveau, A. and Leblanc, J.F. (2011) Tuning of CD40-CD154 Interactions in Human B-Lymphocyte Activation: A Broad Array of In Vitro Models for a Complex in vivo Situation. Archivum Immunologiae et Therapiae Experimentalis, 59, 25-40.

[9] Néron, S., Racine, C., Roy, A. and Guérin, M. (2005) Differential responses of human B-lymphocyte subpopulations to graded levels of CD40-CD154 interaction. Immunology, 116, 454-463. doi:10.1007/s00005-010-0108-8

[10] Stewart, R., Wei, W.B., Challa, A., Armitage, R.J., Arrand J.R., Rowe, M., Young, L.S., Eliopoulos, A. and Gordon, J. (2007) CD154 tone sets the signaling pathways and transcriptome generated in model CD40-Pluricompetent L3055 Burkitt's lymphoma cells. Journal of Immunology, 179, 2705-2712.

[11] Luft, T., Maraskovsky, E., Schnurr, M., Knebel, K., Kirsch, M., Gorner, M., Skoda, R., Ho, A.D., Nawroth, P. and Bierhaus, A. (2004) Tuning the volume of the immune response: Strength and persistence of stimulation determine migration and cytokine secretion of Dendritic 
Cells. Blood, 104, 1066-1074.

doi:10.1182/blood-2003-12-4146

[12] Mathur, R.K., Awasthi, A., Wadhone, P., Ramanamurthy, B. and Saha, B. (2004) Reciprocal CD40 signals through p38MAPK and ERK-1/2 induce counteracting immune responses. Nature Medicine, 10, 540-544. doi:10.1038/nm1045

[13] Ducas, E., Dussault, N., Roy, A., Dumont, N. and Neron, S. (2009) Estimation of the number of CD154 molecules in membrane extracts used as a source of CD40 stimulation of human B lymphocytes. Journal of Immunological Methods, 344, 133-137. doi:10.1016/j.jim.2009.03.009

[14] Fecteau, J.F. and Néron, S. (2003) CD40 stimulation of human peripheral B lymphocytes: Distinct response from naïve and memory cells. Journal of Immunology, 171, 4621-4629.

[15] Fecteau, J.F., Roy, A. and Neron, S. (2009) Peripheral blood $\mathrm{CD} 27(+) \operatorname{IgG}(+)$ B cells rapidly proliferate and differentiate into immunoglobulin-secreting cells after exposure to low CD154 interaction. Immunology, 128, e353-e365. doi:10.1111/j.1365-2567.2008.02976.x

[16] Néron, S., Thibault, L., Dussault, N., Cote, G., Ducas, E., Pineault, N. and Roy, A. (2007) Characterization of mononuclear cells remaining in the leukoreduction system chambers of apheresis instruments after routine platelet collection: A new source of viable human blood cells. Transfusion, 47, 1042-1049. doi:10.1111/j.1537-2995.2007.01233.x

[17] Néron, S., Pelletier, A., Chevrier, M. C., Monier, G., Lemieux, R. and Darveau, A. (1996) Induction of LFA-1 independent human $\mathrm{B}$ cell proliferation and differentiation by binding of CD40 with its ligand. Immunological Investigations, 25, 79-89. doi:10.3109/08820139609059292

[18] Roy, A., Krzykwa, E., Lemieux, R. and Néron, S. (2001) Increased efficiency of gamma-irradiated versus mitomycin C-treated feeder cells for the expansion of normal human cells in long-term cultures. Journal of Hematotherapy \& Stem Cell Research, 10, 873-880. doi:10.1089/152581601317210962

[19] Barbas, I.C.F., Burton, D.R. and Scott, J.K., Silverman, G.J. (2001) Phage display: A laboratory manual. Cold Spring Harbor Laboratory Press, New-York.

[20] Heidt, S., Roelen, D.L., Eijsink, C., Eikmans, M., Claas, F.H.J. and Mulder, A. (2009) Intravenous immunoglobulin preparations have no direct effect on B cell proliferation and immunoglobulin production. Clinical \& Experimental Immunology, 158, 99-105. doi:10.1111/j.1365-2249.2009.03996.x

[21] de Kok, J.B., Roelofs, R.W., Giesendorf, B.A., Pennings, J.L., Waas, E.T., Feuth, T., Swinkels, D.W. and Span, P.N. (2005) Normalization of gene expression measurements in tumor tissues: Comparison of 13 endogenous control genes. Laboratory Investigation, 85, 154-159.
[22] Giricz, O., Lauer-Fields, J.L. and Fields, G.B. (2008) The normalization of gene expression data in melanoma: investigating the use of glyceraldehyde 3-phosphate dehydrogenase and $18 \mathrm{~S}$ ribosomal RNA as internal reference genes for quantitative real-time PCR. Analytical Biochemistry, 380, 137-139. doi:10.1016/j.ab.2008.05.024

[23] Livak, K.J. and Schmittgen, T.D. (2001) Analysis of relative gene expression data using real-time quantitative PCR and the 2(-Delta Delta C(T)) Method. Methods, 25, 402-408.

[24] Proulx, D.P., Aubin, E., Lemieux, R. and Bazin, R. (2009) Spontaneous internalization of IVIg in activated B cells. Immunology Letters, 124, 18-26. doi:10.1016/j.imlet.2009.03.012

[25] Fecteau, J.F. and Néron, S. (2004) Characterization of naïve and memory $\mathrm{B}$ cell differentiation toward Plasma cells following low CD40 stimulation. Immunology Collection of Free Papers. Medimond Srl, Bologna, 303-307.

[26] Bayry, J., Fournier, E.M., Maddur, M.S., Vani, J., Wootla, B., Siberil, S., Dimitrov, J.D., Lacroix-Desmazes, S., Berdah, M., Crabol, Y., Oksenhendler, E., Levy, Y., Mouthon, L., Sautes-Fridman, C., Hermine, O. and Kaveri, S.V. (2011) Intravenous immunoglobulin induces proliferation and immunoglobulin synthesis from B cells of patients with common variable immunodeficiency: A mechanism underlying the beneficial effect of IVIg in primary immunodeficiencies. Journal of Autoimmunity, 36, 9-15. doi:10.1016/j.jaut.2010.09.006

[27] Padet, L., St-Amour, I., Aubin, E., Proulx, D. P., Bazin, R. and Lemieux, R. (2009) Dose-dependent inhibition of BrdU detection in the cell proliferation ELISA by culture medium proteins. Journal of Immunoassay and Immunochemistry, 30, 348-357. doi:10.1080/15321810903084863

[28] van Laar, J.M., Melchers, M., Teng, Y.K.O., van der Zouwen, B., Mohammadi, R., Fischer, R., Margolis, L., Fitzgerald, W., Grivel, J.C., Breedveld, F.C., Lipsky, P.E. and Grammer, A.C. (2007) Sustained secretion of immunoglobulin by long-lived human tonsil plasma cells. The American Journal of Pathology, 171, 917-927. doi:10.2353/ajpath.2007.070005

[29] Hommes, O.R., Haas, J., Soelberg-Sorenson, P. and Friedrichs, M. (2009) IVIG trials in MS. Is albumin a placebo? Journal of Neurology, 256, 268-270. doi:10.1007/s00415-009-0893-3

[30] Ho-Pun-Cheung, A., Cellier, D. and Lopez-Crapez, E. (2008) Considerations for normalisation of RT-qPCR in oncology. Ann Biol Clin (Paris), 66, 121-129.

[31] Mane, V.P., Heuer, M.A., Hillyer, P., Navarro, M.B. and Rabin, R.L. (2008) Systematic method for determining an ideal housekeeping gene for real-time PCR analysis. $J$ Biomol Tech, 19, 342-347. 